ARTÍCULOS 



\title{
LAS POLITTICAS DE IMPLANTACIÓN DEL RIEGO LOCALIZADO. EFECTOS EN LAS ENTIDADES DE RIEGO DE LA COMUNIDAD VALENCIANA
}

\author{
Carles Sanchis Ibor \\ Marta García Mollá \\ Llorenç Avellà Reus \\ Centro Valenciano de Estudios del Riego. Universitat Politècnica de València \\ csanchis@hma.upv.es, mgarmo@esp.upv.es, lavella@esp.upv.es
}

\section{RESUMEN}

Durante los últimos treinta años, las administraciones públicas y las entidades de riego han efectuado un importante esfuerzo destinado a modernizar los regadíos valencianos. Esta política hidráulica, consecuencia de la adopción de un modelo de gestión de la demanda, se ha materializado en una importante expansión del riego por goteo. El artículo analiza, a partir de diversas entrevistas, los efectos de la modernización sobre unas entidades de riego que han experimentado cambios en la eficiencia del riego, organización, usos y costos de agua.

Palabras clave: regadíos, modernización, riego por goteo, gestión de la demanda, política hidráulica.

\section{ABSTRACT}

During the last 30 years, regional and central administrations and farmers have done an important financial effort in order to promote irrigation modernization in the Valencia Region. This policy, a corollary of a National investment on demand management, has been materialized in an important expansion of drip irrigation techniques. The aim of this

Fecha de recepción: septiembre 2014.

Fecha de aceptación: junio 2015. 
article, based on numerous interviews, is to analyze the effects of this policy on water user's associations, which have undergone significant changes in water supply, organization, irrigation efficiency and water costs in the last decades.

Keywords: irrigation, modernization, drip irrigation, demand management, water policy.

\section{INTRODUCCIÓN}

A lo largo de las últimas tres décadas el regadío valenciano ha experimentado una profunda transformación, derivada de la generalización de las tecnologías de riego presurizado. Muchas de las antiguas acequias, en algunos casos construidas durante el periodo islámico, han sido reemplazadas por las conducciones a presión en algo más de 180.000 hectáreas. Canales, partidores y boqueras han dado paso a tuberías, gomas y goteros, mientras que centenares de balsas y casetas de control han irrumpido masivamente en el paisaje agrario valenciano. En paralelo, prácticas hidráulicas y agronómicas inveteradas están siendo abandonadas, como resultado de una transformación que además de modificar las infraestructuras, afecta a los procedimientos operativos del riego. Se trata de un cambio tecnológico sin precedentes en el campo valenciano, que ha alterado notablemente los paisajes regados y las formas de organización social del riego, en aras de una mayor eficiencia hidráulica y económica. Este proceso de cambio tecnológico se enmarca en un conjunto de acciones desplegado en numerosas regiones semiáridas del mundo durante el último cuarto del siglo XX. Tras un prolongado periodo de aplicación de un modelo de gestión de la oferta de agua, en la que los poderes públicos mostraron una enorme implicación en el desarrollo y expansión de las zonas regadas, en los últimos años se ha asistido a un giro en las políticas hidráulicas hacia el modelo denominado de gestión de la demanda, que persigue la reducción del consumo de agua a través de diversos mecanismos, entre los que destaca la incorporación de tecnologías ahorradoras (Seckler, 1996; Winpenny 1997; Brooks 1997).

En el caso español, han sido numerosos los autores que han descrito el compromiso adquirido por la administración del estado en el desarrollo de una política expansiva del regadío a lo largo del siglo XX, mediante la creación de una poderosa burocracia hidráulica y la financiación de numerosas obras públicas (Melgarejo, 1995; López Ontiveros, 1997; Ortega, 1999; Swyngedouw, 1999; Saurí y Del Moral, 2001; López-Gunn, 2009). Estas acciones, plasmación del ideario regeneracionista, constituyeron un éxito en términos de sostenimiento de la renta agraria, pero llevaron a algunas cuencas peninsulares a una situación límite en cuanto a la disponibilidad de recursos hídricos, o bien generaron graves impactos sobre los ecosistemas hídricos (Martínez y Esteve, 2002; Sanchis et al., 2011; López-Gunn et al., 2012a).

Durante las dos últimas décadas, como consecuencia de los problemas ambientales y sociales generados por la persistente aplicación de este paradigma hidráulico, la política española está efectuando una compleja transición hacia modelos de uso del agua más sostenibles, cuyo punto de inflexión algunos autores sitúan en la Ley de Aguas de 1985 y otros en el fallido Plan Hidrológico de 1993 (Carles y García-Mollá, 2003; Del Moral, 2009). No debe olvidarse, no obstante, el impacto social causado por la sequía del periodo 1992-1995, cuyas consecuencias sobre la agricultura y abastecimientos urbanos ha demostrado tener un 
efecto catárquico en el comportamiento de los agentes público-privados en la gestión del agua en España (López-Gunn et al., 2012b; García-Mollá et al., 2013). A lo largo de este periodo, en consecuencia, se vienen solapando acciones encaminadas a incrementar sustancialmente la oferta hídrica con otras destinadas a reducir la demanda de agua y a mejorar la calidad del recurso, en un contexto social y político sumamente enrevesado (Estevan, 2008; López-Gunn, 2009; Morales y Hernández, 2010; Rico, 2010; Swingedouw, 2013).

En los regadíos españoles, las políticas de ahorro han ido progresivamente desplazando de los planes y presupuestos públicos a las acciones de ampliación de la superficie regable, circunscritas en los últimos años a ámbitos geográficos muy concretos o a determinados cultivos, como ha sido el caso de la viña o el olivar. Los sucesivos planes de la administración pública aprobados en la pasada década (Plan Nacional de Regadíos, 2002; Plan de Choque de Modernización de Regadíos, 2006; Plan de Cierre, 2007) tenían como objetivo poner en riego localizado algo más de 2 millones de hectáreas, con una inversión total de más de 5.000 $\mathrm{M} €$, de los que la inversión pública era de cerca de 3.400M€ (Naranjo, 2010). Según este autor las cifras de inversión previstas se han rebasado con creces, al menos en lo que respecta a la administración central del Estado. En algunas comunidades autónomas, las administraciones regionales han efectuado también un importante esfuerzo inversor, como en Aragón (Frutos Mejía et al., 2008), Andalucía (Corominas, 2011), o en las cuencas del Segura, el Tajo y el Duero (Gómez Espín, 1997 y 2011).

En líneas generales la introducción de tecnologías ahorradoras de agua se ha manifestado con mayor intensidad en aquellos territorios con un balance más desfavorable entre recursos y usos. En estas condiciones, y singularmente en aquellas comarcas con un importante déficit hídrico, la mejora de la eficiencia de riego deviene una estrategia fundamental para intentar corregir tales desequilibrios. En este sentido, diversos trabajos han destacado que la necesidad de incrementar la garantía de suministro de los regadíos ha sido, por encima de otros factores, la principal motivación de incorporación de estas tecnologías por el sector agrario (Escribano, 2006; Corominas, 2008; Alcón et al, 2009).

No obstante, algunos autores han cuestionado que la mejora de la eficiencia técnica sea prácticamente la única vía adoptada en los proyectos impulsados por el sector público, relegando otras posibles mejoras en la gestión del recurso. Este tipo de intervenciones son más fáciles de ejecutar, en términos políticos, que la intervención en los mecanismos de asignación del recurso (Allan, 1999; Venot et al, 2014). Captan el interés de los agricultores y también el de la construcción y la industria asociada al sector, sin apenas resistencia social ni peajes políticos.

En consecuencia, se ha asistido a un cambio tecnológico muy rápido, que en muchas ocasiones se ha desarrollado sin un análisis previo de las condiciones y requerimientos agronómicos y socio-económicos de las explotaciones, ni de las repercusiones a escala de cuenca, ni mucho menos sobre los impactos sobre el patrimonio o los ecosistemas adyacentes. No ha habido, como señalan López-Gunn et al. (2012c) al aplicar la teoría del ciclo político a los procesos de modernización, un análisis ex ante suficientemente riguroso, tampoco programas de control o seguimiento, y en muy pocas ocasiones se ha efectuado un análisis ex post.

En las siguientes líneas pretendemos analizar las consecuencias que la incorporación de estas tecnologías ha tenido sobre las entidades de riego de la Comunidad Valenciana. En primer término, se expondrán los estudios que recientemente han abordado las implicaciones 
de la transformación a riego por goteo, en el conjunto del estado español y en otros países. Seguidamente se describen las particularidades y magnitudes el proceso de modernización de los regadíos valencianos durante los últimos treinta años y, por último, se analiza con detalle los efectos que este proceso de cambio tecnológico ha tenido sobre las entidades de riego. Este trabajo se ha desarrollado fundamentalmente a partir de entrevistas con los responsables de diversas comunidades de regantes, comunidades generales y juntas centrales de usuarios, de las cuales 6 pertenecen a la cuenca del Mijares, 1 a la del Palancia, 2 a la del río Turia, 8 a la del Júcar, 1 a la del Serpis, 8 a la del Vinalopó y 4 a la del río Segura.

\section{LOS EFECTOS DE LA PRESURIZACIÓN DE LOS SISTEMAS DE RIEGO}

El ahorro de agua ha sido la principal motivación para la introducción de las tecnologías de riego presurizado en numerosos espacios áridos y semiáridos. La capacidad de los sistemas de riego localizado para reducir el consumo de las parcelas sin menoscabar la satisfacción de las necesidades hídricas de los cultivos ha sido sobradamente testada en condiciones de laboratorio y en parcelas experimentales. Por ello, numerosos autores han respaldado la puesta en marcha de las políticas de modernización del regadío en España como un elemento clave para reducir el consumo de agua (Gallego, 1996; Gómez Espín, 1997; Gil Olcina y Del Amor, 2004; Gómez Espín et al, 2007b; Gil Meseguer, 2010). Estas tecnologías permiten disminuir las pérdidas en las conducciones, aseguran una detección precoz de las fugas y contribuyen a mejorar la planificación de la distribución del recurso, por lo que, por lo general, las entidades de riego consiguen incrementar notablemente la eficiencia en la distribución y aplicación del recurso.

Sin embargo, durante los últimos años, algunos autores han detectado una disparidad entre los objetivos de ahorro asociados a la aplicación de las tecnologías de riego y el consumo final del recurso, basándose en la diferente percepción que se obtiene de la eficiencia cuando este concepto se considera localmente o desde una perspectiva de la gestión integrada de recursos (Seckler, 1996; Perry, 1999). En este sentido, se puede dar la paradoja que la introducción de tecnologías ahorradoras redunde en un incremento del consumo a escala de cuenca, como han sugerido Ward y Pulido (2008) o Hardy y Garrido (2010), al considerar que la mejora local de la eficiencia del riego impide que los sobrantes o retornos de riego sean utilizados por otros usuarios, los cuales tendrían que recurrir a movilizar nuevos recursos.

Autores como Playán (2002), Playán y Mateos (2006), Perry et al. (2009), Lecina et al. (2010a), Cots (2011) o Sese (2013) han señalado diversos escenarios en los que la introducción de las tecnologías ahorradoras también podría tener un efecto contrario al deseado. En primer lugar, la modernización de regadíos puede llevar aparejada una intensificación de los cultivos, hacia variedades más productivas y más exigentes hídricamente, hecho que incrementaría la EVT y el consumo de agua. A su vez, con relativa frecuencia, el agua ahorrada localmente se destina a satisfacer nuevas demandas o a ampliar la superficie regada, con lo que a escala de cuenca no se reduciría el consumo, si bien en algunos casos se optimizaría su uso económico.

Resulta muy difícil encontrar trabajos que cuantifiquen con precisión el ahorro generado por la introducción de estas infraestructuras a partir de datos obtenidos de las comunidades 
de regantes. Se trata de una comparación aparentemente fácil de obtener, pero que en realidad se ve dificultada por la influencia de otras variables. Las variaciones en la superficie regada o los cambios en las producciones -que como hemos señalado se suelen asociar a los procesos de modernización- dificultan la obtención de estos datos. Además en ocasiones, en determinadas comarcas deficitarias, el uso del agua tiene una relación directa con las disponibilidades anuales -se utiliza siempre toda el agua disponible cada campaña-, por lo que las nuevas tecnologías pueden mejorar la eficiencia de las explotaciones, la producción y la garantía de suministro, pero su introducción no acaba reflejándose en un descenso de los volúmenes utilizados anualmente por el conjunto de la entidad de riegos. Por último, durante los últimos años, el incremento de los costes energéticos ha forzado a muchos regantes abastecidos con aguas subterráneas a reducir el número de bombeos (Corominas, 2009, López-Gunn et al., 2012c) estimulando un ahorro en zonas recientemente modernizadas que no tiene origen en el proceso de cambio tecnológico y que por tanto, enmascara su impacto.

La mejora de la productividad del agua es para autores como Gallego (1996) una consecuencia más importante que el ahorro del recurso. La ventaja competitiva que adquieren las explotaciones que adoptan estos sistemas de riego justifica por sí sola la promoción pública del cambio tecnológico. Lecina et al. (2010b) han comprobado estos efectos en el caso de los Riegos del Alto Aragón y Gil Meseguer (2010) y Gómez Espín et al. (2007a) extraen conclusiones similares de los regadíos murcianos. Ahora bien, tanto unos como otros advierten de los riesgos que pueden tener estas inversiones, debido a que factores como las fluctuaciones de los mercados agrarios, los precios de la energía o los desequilibrios entre disponibilidades y demandas hídricas generan una notable incertidumbre sobre el futuro de muchas explotaciones agrarias (López Fernández y Gómez Espín, 2008).

Incluso en este contexto desfavorable, hay otros efectos asociados a la implantación de estas tecnologías que sirven de estímulo a su generalización. Entre ellos, Gómez Limón et al (2012) han destacado la reducción de costes laborales. En este sentido, si hay un aspecto que suscita un significativo consenso entre los agricultores que hemos entrevistado en los últimos años, es el confort y la mejora de calidad de vida que provoca la instalación de sistemas de riego presurizado. La posibilidad de adoptar sistemas de riego a demanda -con la consiguiente supresión del riego nocturno-, la introducción de la fertirrigación, y la reducción de las tareas de preparación de la tierra para el riego, generan una notable reducción de las horas de trabajo que redunda de forma muy variable en los costes de explotación, pero que disminuye notablemente el número de horas de trabajo y permite una mejor compatibilidad con la vida privada y con otras actividades laborales. Gil Meseguer (2010) ha destacado además la flexibilidad que en ocasiones supone para los agricultores, singularmente en hortícolas intensivos, la posibilidad de trasladar las zonas regadas de unas parcelas a otras extendiendo y recogiendo los goteros cada vez que resulta necesario.

Otras cuestiones, como las repercusiones sobre el consumo energético, no deparan tanta unanimidad entre autores o usuarios. Algunos trabajos han detectado un importarte ahorro energético en comunidades de regantes que, al abastecerse de aguas subterráneas y disponer de una red de riego obsoleta, consiguen un importante ahorro de energía al transformar y racionalizar el sistema de riego, aprovechando las ventajas de las tecnologías de riego localizado para programar más adecuadamente las extracciones y bombeos. Este es el caso, por ejemplo, de los estudios realizados por Gómez Espín (1997) sobre el Plan de Modernización 
de los Riegos de Jumilla y la comunidad de regantes del Pantano de la Cierva, donde registra un descenso de los costos energéticos de hasta un $40 \%$ como consecuencia de la modernización del sistema de riegos. Similares resultados se han obtenido recientemente en las entidades de riego del acuífero Ascoy-Sopalmo (Murcia) (Gómez Espín et al, 2007a). Asimismo, Gómez-Limón y Picazo-Tadeo (2012) afirman que recientes experiencias muestran que la introducción de nuevas tecnologías puede reducir significativamente los costes energéticos, un factor que junto a la reducción de costes laborales y el ahorro de agua justifica el desarrollo de las políticas públicas de implantación de riegos.

Sin embargo, Hardy y Garrido (2010) mantienen que la modernización de los regadíos en España ha conllevado un aumento del consumo eléctrico de las explotaciones agrarias, hecho que ha resultado particularmente lesivo en un contexto de subida de los precios de la energía y que hace necesario situar la eficiencia energética en el centro de las políticas de modernización. Rodríguez-Díaz et al. (2011) han aportado datos de campo que sustentan esta reflexión, a partir de un estudio realizado en la cuenca del Bembézar (Córdoba). Allí, han observado un incremento de los costes energéticos de resultas de la transformación a riego presurizado, hasta alcanzar el $40 \%$ de los costes del riego. Los costes de operación y mantenimiento del sistema aumentaron considerablemente $(400 \%)$ ya que la energía requerida para presurizar la red hidráulica es mucho mayor a la empleada en el sistema de gravedad. La comparación de estos resultados, sobre riegos de aguas superficiales en el Guadalquivir, con los obtenidos por los trabajos efectuados en aguas subterráneas en Murcia (Gómez Espín, 1997), no es contradictoria. De hecho, estudios efectuados en Australia (Jackson et al., 2010) concluyen que es frecuente obtener una reducción de consumo energético en los regadíos de aguas subterráneas, mientras que en zonas abastecidas por aguas superficiales la presurización trae consigo un incremento de los costes energéticos y por ende, los del riego. En estos casos llegan a recomendar centrar los esfuerzos en la mejora de los sistemas de riego por gravedad, evitando la presurización de la red.

Así y todo, incluso en los ámbitos de aguas subterráneas o mixtas, como pone de relieve el reciente trabajo de Sese (2012) en la cuenca del Cànyoles (Valencia), también es posible encontrar ejemplos de entidades que han visto incrementar sus costes energéticos. Por ello, ante el actual contexto de precios eléctricos, el desarrollo de una completa auditoría energética de los proyectos resulta imprescindible a la hora de implementar acciones de modernización de regadíos, tal y como sugieren Carrillo-Cobo et al. (2010).

En algunos casos este incremento de costes del riego generado por la energía puede ser compensado a escala de las explotaciones, en una cuantía muy variable, por la citada reducción de costes laborales o por una reducción de los costes de abonado, debido a la ventaja que suponen los sistemas de fertirrigación. Según informaciones recogidas por López-Gunn et al. (2012c) estos pueden reducirse entre un 25\% y un 50\%. Además, esta disminución de los inputs, derivada de una gestión centralizada del abonado y de una programación mejor planificada, redunda también en una reducción del impacto de determinados nutrientes tiene sobre los acuíferos subyacentes o los ecosistemas fluviales o albufereños situados en cola del sistema de riegos. No obstante, como hemos podido comprobar en diversas entrevistas, en ocasiones los agricultores complementan estos aportes con otros, muy variables, aplicados en parcela, lo que podría alterar el total real de nutrientes utilizados y minimizaría la mejora en la difusión de contaminantes. 
Por otra parte, cuando los sistemas de riego presurizado se instalan sobre regadíos tradicionales se suele producir el abandono de las redes históricas de regadío, con el consiguiente perjuicio para la conservación del patrimonio hidráulico. El deterioro o la pérdida de los artefactos hidráulicos tradicionales por dicha causa, avanzada por Gil Meseguer (2010) y comprobada sobre el terreno por Sese (2012), nunca es considerada a la hora de tomar decisiones sobre la implementación de los sistemas de presurización y su impacto. De la misma manera, el mantenimiento de las redes tradicionales de drenaje y avenamiento, fundamental para la reducción de la peligrosidad de los procesos de inundación en determinadas áreas, apenas ha sido considerada en la literatura científica (Sales, 1999).

En definitiva, las políticas de promoción de los riegos presurizados, destinadas inicialmente a incrementar la eficiencia hídrica y económica del regadío, presentan una serie de efectos inesperados que han sido puestos de relieve por diversos estudios recientes. Estos trabajos muestran en algunos casos conclusiones aparentemente contradictorias. La realidad es que, en primer término, como acertadamente señalan López Gunn et al (2012c), estas respuestas evidencian la carencia de un adecuado análisis previo al desarrollo de estas políticas y una ausencia de mecanismos de seguimiento de sus resultados. En segundo lugar, la revisión de los trabajos realizados hasta el momento pone de relieve la variabilidad geográfica y agronómica de los regadíos peninsulares, y el diferente impacto que este proceso de cambio tecnológico puede tener sobre diferentes sistemas de riego, en función de numerosos factores, como su diseño, tipo y origen del recurso empleado, cultivos, antigüedad, estado de conservación, etcétera.

Como sugieren Allan (1999) o Playán (2002) o Lecina et al. (2010b), cabría cuestionarse que las administraciones públicas hayan centrado todos sus esfuerzos en la eficiencia técnica, cuando no en la presurización de las redes de riego, como la única vía para reducir la demanda de agua, dejando de lado otras vías de mejora de la gestión local del riego. De este modo, en lugar de prestar una asistencia técnica a los regantes para analizar en cada caso que mejoras podrían introducirse, se ha optado por poner a disposición de los usuarios una línea de subvenciones a la modernización, bajo una escasa o nula supervisión externa. Incluso en muchas ocasiones no han existido acciones de formación o de asistencia técnica paralelas, algo que ha sido reivindicado por diversos autores (Gil Meseguer, 2010; Alarcón, 2011) como un elemento clave para conseguir los efectos deseados en los proyectos de modernización de regadíos.

\section{LA MODERNIZACIÓN DEL REGADÍO VALENCIANO}

A lo largo de las últimas tres décadas, las administraciones públicas y las entidades de riego han apostado claramente por la modernización del regadío en la Comunidad Valenciana. El regadío valenciano, en franca expansión hasta hace pocos años, ha tenido que hacer frente a un contexto de creciente presión sobre los recursos hídricos. Con unos ríos que pese a su intensa regulación no ofrecían garantías de suministro para muchas entidades de riego y con varios acuíferos sobreexplotados o con graves problemas de intrusión marina, la agricultura valenciana se vio abocada a emprender un importante esfuerzo destinado a disminuir el consumo de agua. 
El proceso de introducción del riego localizado en la región fue previo a los programas públicos de apoyo. La primera instalación documentada tuvo lugar en la finca «Las Garroferas», en la Vega Baja del Segura (Ramón Morte, 1995). Diez años después, en 1982, el riego por goteo se había extendido sobre 5.556 ha, principalmente en abancalamientos de laderas para la citricultura abastecidos por aguas subterráneas y en la transformación de secanos en frutales y viñedos de las comarcas meridionales (Ramón Morte, 1994, 1995).

En 1986, la Ley de la Generalitat Valenciana 7/1986 sobre la utilización de aguas para riego, destinada a estimular la utilización racional del agua en los regadíos valencianos, reguló la tramitación de las ayudas públicas destinadas a la modernización de las entidades de riego y puso las bases para una colaboración continuada entre los usuarios agrícolas del agua y la administración regional. Sin embargo, entre 1987 y 1995, sólo 37 de las 611 acciones financiadas en diferentes entidades de riego fueron destinadas a la transformación a riego localizado. De ellas además, la mitad se iniciaron ya en 1994 (Figura 1).

Es en estas fechas, en el momento más crítico de la sequía de los años 1994-1995, y tras el fracaso del proyecto de Plan Hidrológico Nacional de 1993, cuando la administración valenciana apostó por intensificar sus esfuerzos en materia de implantación del riego localizado, como solución a la incertidumbre climática y política en materia de recursos hídricos. Así, el 10 de enero de 1995 se aprobó el Plan Director de Modernización del Regadío de la Comunidad Valenciana, cuyo texto comienza admitiendo una situación de déficit creciente que en algunas comarcas presenta «tintes dramáticos» y cuya solución «no debe reducirse a los transvases intercuencas, sino que, al menos parcialmente, debe ser acometida desde la propia Comunidad Valenciana a través de una estrategia de ahorro, reutilización y mejora de la eficiencia del agua para riego» ${ }^{1}$.

A partir de este momento, y en paralelo a un importante esfuerzo inversor en materia de reutilización de aguas residuales (Melgarejo, 2009), se inicia una nueva etapa en la modernización de regadíos, en la que la difusión de las tecnologías de riego localizado ha tenido un papel preponderante. La apuesta por el riego por goteo presenta además una clara articulación política, en tanto en cuanto la eficiencia y productividad del riego se convirtieron en premisa y estandarte de las reivindicaciones de transferencia de recursos hídricos, como en los casos del Ebro y el Vinalopó. Era necesario demostrar que se aprovechaba hasta la última gota de agua para poder aspirar a obtener nuevos recursos, o bien para poder sobrevivir sin ellos. Se estableció así un nexo entre las políticas de gestión de la demanda y de la oferta, aparentemente contradictorio desde una perspectiva teórica, pero con una lógica aplastante desde la óptica de los usuarios agrícolas, y desde luego, irresistible para los estrategas electorales. Por todo ello, los regantes valencianos no han dejado de movilizarse para reclamar la obtención de mejores dotaciones, ni de esforzarse en la mejora de la eficiencia del uso del agua.

En definitiva, las políticas de generalización de las tecnologías ahorradoras de agua se vieron sustentadas tanto por aquéllos que defendían una rápida transición hacia modelos de uso más sostenible, como por los partidarios de incrementar provisión de recursos. Se tejió así un poderoso discurso en torno al concepto de «modernización» del riego, respaldado por

1 Decreto 13/1995 del Gobierno Valenciano, http://hispagua.cedex.es/sites/default/files/hispagua_ legislacion/275.htm. 
documentos internacionales, por los ahorros estimados en los estudios científicos de eficiencia del riego, por la capacidad seductora de la noción de modernidad y por la necesidad de lavar la imagen de unos regadíos muchas veces injustamente tildados de derrochadores. Además, muchos agricultores valoraron también las ventajas que la incorporación de las redes de presurización podían reportar sobre el uso de fertilizantes y la adopción de prácticas de riego más confortables.

A esta alianza de intereses entre la administración pública y los usuarios agrícolas del agua se sumaron los colectivos profesionales y empresariales beneficiados por la instalación y mantenimiento de las nuevas infraestructuras, estimulando la rápida generalización de las nuevas tecnologías de riego. En algunos casos incluso, fueron los departamentos comerciales de las empresas de sistemas de presurización los que se dirigieron a las comunidades de regantes para que pusieran en marcha el proyecto de modernización, asesorándoles en la tramitación de la solicitud de subvención.

Como resultado de esta nueva orientación de la política hidráulica, durante el lustro siguiente se disparó el número de intervenciones de transformación a riego localizado en la Comunidad Valenciana (Figura 1). Sólo en el periodo 1996-2000 se financiaron 434 obras en distintas entidades de la región, a las que hay que sumar otras 431 hasta que la crisis financiera de 2008 paralizó las inversiones del gobierno autonómico. Estas actuaciones se ejecutaron en paralelo a nuevas obras de revestimiento de canales, centradas casi exclusivamente en unos regadíos tradicionales donde la implantación del riego localizado presentaba mayores inconvenientes y resistencias.

Tal como muestra la figura 2, el proceso de modernización se inició con más fuerza en las entidades que riegan únicamente con aguas subterráneas. En ellas, los estímulos para la transformación eran mayores, en buena medida porque los costes del riego eran más elevados y suponían un aliciente para mejorar la eficiencia, pero también por otros motivos, como las unas mejores posibilidades para la ampliación de la superficie regada, imposible en los regadíos tradicionales y difícil en los mixtos ejecutados con planes del estado (Carles, 1997). Las entidades abastecidas con aguas subterráneas han continuado siendo las más beneficiadas por las inversiones de transformación, pero durante la última década se observa una mayor aceptación de estas tecnologías ahorradoras en las entidades que aprovechan aguas superficiales o mixtas.

La administración central del estado no ha sido ajena a este esfuerzo inversor y a través de diversas instituciones ha contribuido con apoyo técnico y financiero a la modernización de los regadíos valencianos y la presurización de sus redes de riego. Además, con el fin de coordinar sus actuaciones con la Generalitat Valenciana, las dos administraciones intervienen conjuntamente mediante un acuerdo marco de colaboración (BOE 151, 25 de junio de 2002) que se concreta para cada acción individual, subvencionando y financiando parcialmente la inversión en las redes colectivas de riego. La tarea de cuantificar para cada obra las administraciones que participan en la financiación de las inversiones y el origen de los fondos es realmente compleja. Hay intervenciones ejecutadas únicamente por la administración central del estado (financiadas al 100\%) y la Generalitat Valenciana también ha concedido inversiones directas en aquellas zonas que han sido declaradas de «interés general» y que son planificadas, ejecutadas y financiadas completamente por la administración regional. Asimismo, la Generalitat ha otorgado subvenciones a las entidades de riego que deseaban realizar por sí 
mismas las obras de racionalización y mejora del regadío y a las actuaciones realizadas en el interior de las parcelas (40\% de la inversión). En ocasiones, estas ayudas han sido cofinanciadas con aportes procedentes de fondos europeos.

En consecuencia, existen grandes diferencias en la inversión total -pública y privadapor hectárea modernizada, que también pueden estar justificadas por los distintos tipos de obras realizadas. Por otro lado, también son notables las diferencias en el porcentaje de subvención con respecto a la inversión total. Esto es debido a que han sido subvencionadas por distintas administraciones que cuentan con diversos programas con porcentajes diferentes de subvención de la inversión (Tabla 1).

El impacto de esta inversión ha sido notable. Si en 1992 existían 50.255 ha en la región -la mitad de las cuales se localizaba en la comarca de la Vega Baja del Segura-, en 1999 se duplicó esta superficie hasta las 101.157 ha, y en 2012 se alcanzaron las 181.289 ha (MAGRAMA). Tal como se muestra en la figura 3, el incremento de la superficie regada por goteo fue acompañada de un aumento de las tierras de regadío hasta 2008. A partir de ese año se observa un descenso de la superficie regada, que hoy día es fácil constatar sobre el terreno en diversas comarcas valencianas. También el Censo Agrario muestra una disminución de la superficie regada entre 1999 y 2009. Las razones que podrían explicar esa disminución son el abandono de parcelas, el descenso de la rentabilidad (bajos precios y altos costes en algunos cultivos, sobre todo algunas variedades de cítricos, frutales y viñedo), ausencia de relevo generacional y recalificación urbanística y expropiación de suelo agrario para infraestructuras. Este descenso parece cebarse principalmente en los sistemas de riego por gravedad, cuya merma se debe tanto al abandono de las explotaciones, como por su paso a riego presurizado.

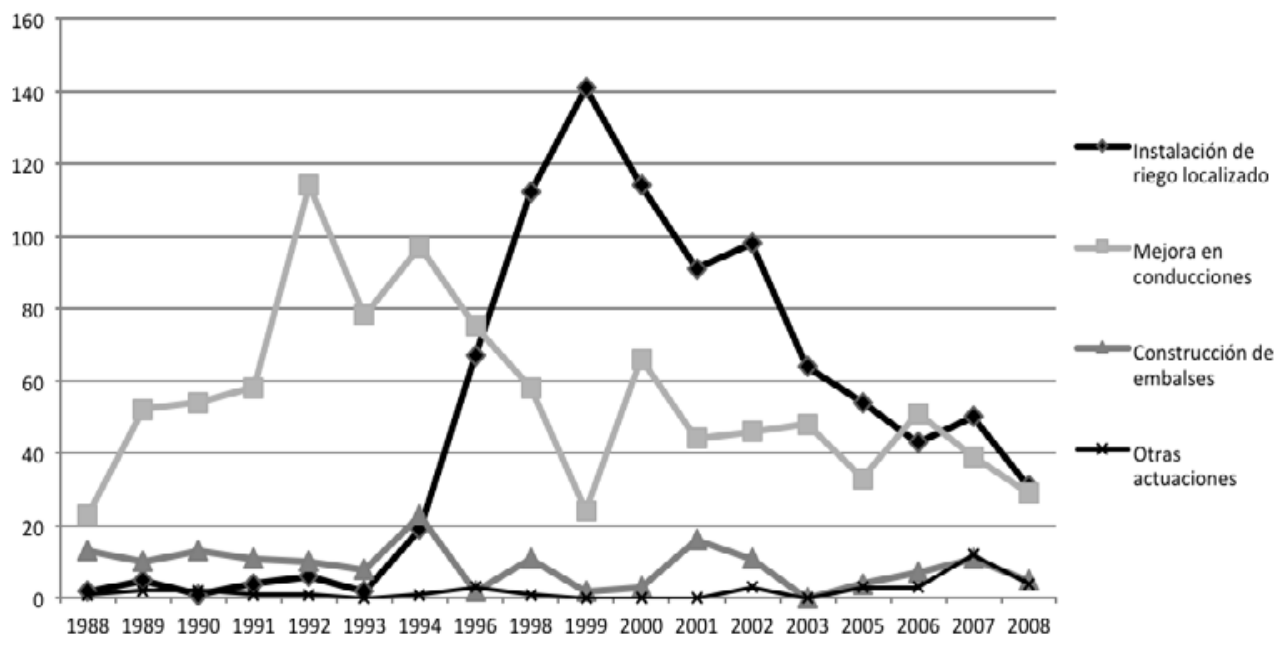

Fuente: elaboración propia a partir de datos del Diario Oficial de la Comunidad Valenciana. 
Figura 2

SUPERFICIE MODERNIZADA POR TIPO DE ENTIDAD Y PERIODO (HECTÁREAS)

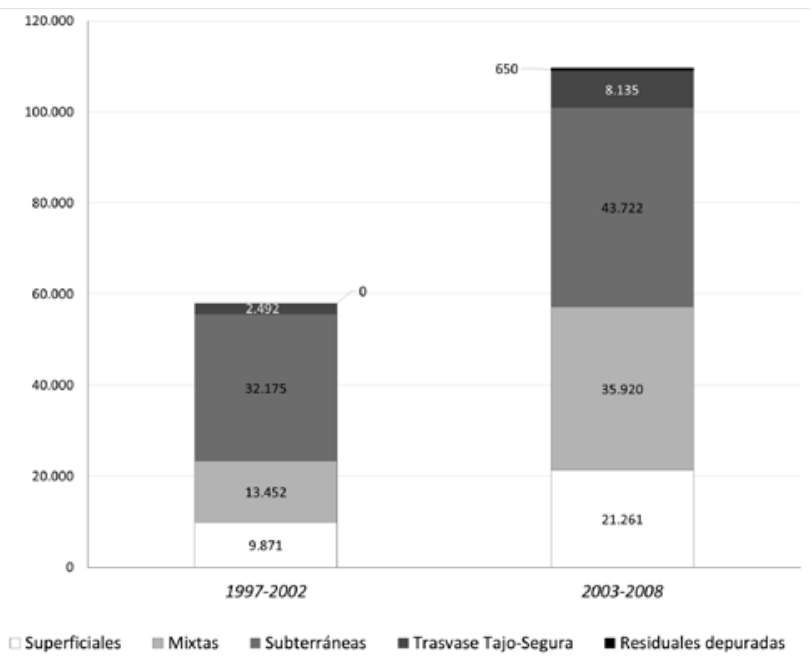

Fuente: elaboración propia a partir de los datos de la Conselleria de Agricultura y SEIASA Meseta Sur.

Tabla 1

SUBVENCIONES APLICADAS A LAS TRANSFORMACIONES

A RIEGO LOCALIZADO EN DIVERSOS ÁMBITOS DE LA COMUNIDAD VALENCIANA

\begin{tabular}{|c|c|c|c|c|}
\hline & $\begin{array}{l}\text { Superficie (ha) } \\
\text { en goteo }\end{array}$ & Inversiones/ ha & Subvenciones/ha & $\begin{array}{c}\text { Porcentaje } \\
\text { subvencionado }\end{array}$ \\
\hline \multicolumn{5}{|l|}{ Júcar } \\
\hline Canal Júcar-Turia & 564 & 6.949 & 4.725 & $68 \%$ \\
\hline \multicolumn{5}{|l|}{ Mijares-La Plana } \\
\hline SCARM & 8.149 & 9.547 & 4.541 & $48 \%$ \\
\hline CGRVU & 1.892 & 8.501 & 5.293 & $62 \%$ \\
\hline \multicolumn{5}{|l|}{ Palancia } \\
\hline Mixtas & 1.663 & 19.327 & 13.445 & $70 \%$ \\
\hline Subterráneas & 474 & 5.586 & 2.261 & $40 \%$ \\
\hline \multicolumn{5}{|l|}{ Turia } \\
\hline Bètera & 3.050 & 4.320 & 3.021 & $70 \%$ \\
\hline \multicolumn{5}{|l|}{ Vinalopó-Alacantí } \\
\hline Monforte del Cid & 1.972 & 13.016 & 10.053 & $77 \%$ \\
\hline
\end{tabular}

Fuente: elaboración propia a partir de información obtenida en entrevistas. SCARM: Sindicato Central de Aguas del Río Mijares y CGRVU: Comunidad General de Regantes de la Vall d’Uixó. 


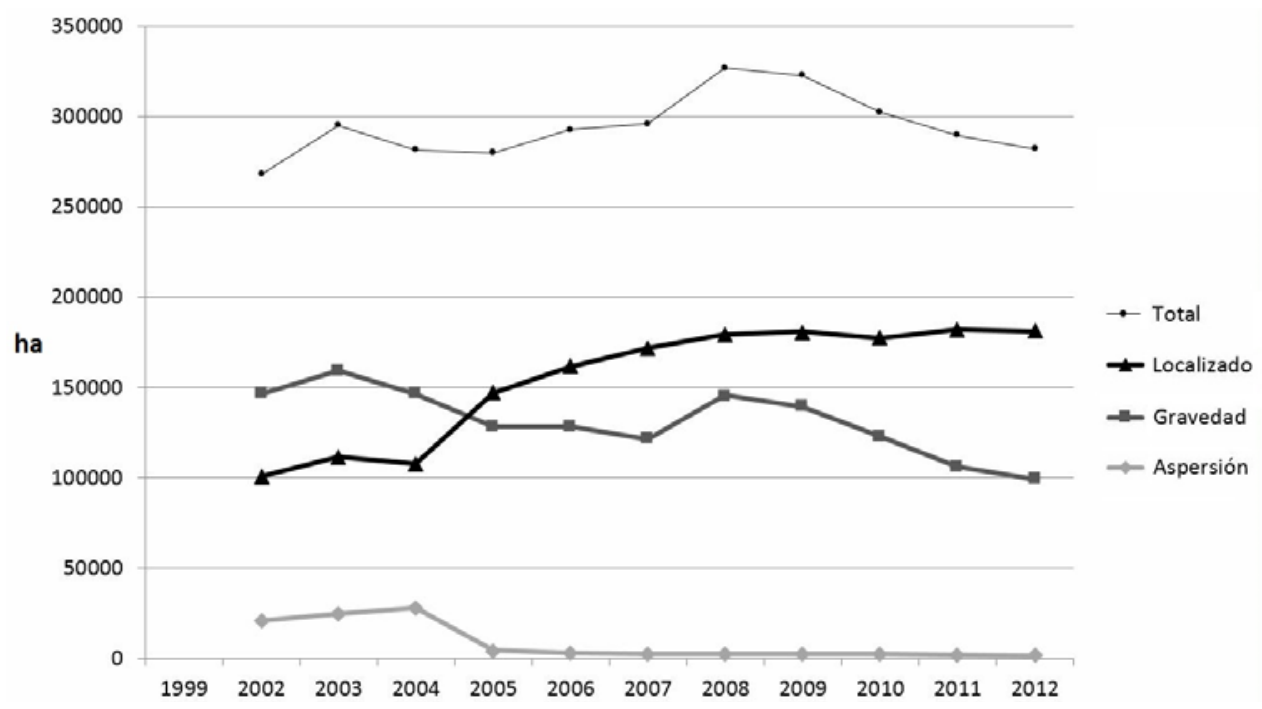

Fuente: MAGRAMA (ESYRCE) (Varios años).

\section{EFECTOS OBSERVADOS EN LAS COMUNIDADES DE REGANTES}

\section{IV.1. Ahorros en los aportes de agua para riego}

La principal motivación de las administraciones públicas para la instalación de riego por goteo, aunque no la única, ha sido la necesidad de ahorrar agua en el riego. Aunque existen estudios que ponen en duda que se consigan ahorros en las cuencas hidrográficas, según los datos ofrecidos por las entidades de regantes que hemos entrevistado, los ahorros conseguidos son importantes en las parcelas y red de distribución. En general, se observa que en las zonas dónde los aportes eran mayores antes de la modernización se consiguen unos ahorros mayores. En el municipio de Vall d'Uixó, regado por entidades que únicamente utilizan aguas subterráneas, los aportes medios del riego antes del cambio de técnica de riego superaban los $9.000 \mathrm{~m}^{3} /$ ha anuales e incluso llegaban a los $17.000 \mathrm{~m}^{3} / \mathrm{ha}$ en algunas entidades. La media de los aportes de agua con el riego por goteo está sobre los $4.100 \mathrm{~m}^{3} /$ ha y el máximo no llega a los $5.000 \mathrm{~m}^{3}$. Tras la modernización se ha detectado un aumento de los niveles piezométricos confirmados por la Confederación Hidrográfica del Júcar (2010), aunque no ha habido disminuciones significativas en los niveles de salinidad del agua extraída.

En una zona colindante a esta, en la provincia de Castellón, las entidades de riego tradicionales con aguas superficiales y mixtas también se observan reducciones muy importantes de los consumos. Pasando de una media de $8.600 \mathrm{~m}^{3} /$ ha y año antes de la modernización a 
$3.850 \mathrm{~m}^{3} /$ ha tras el proceso, siendo el aporte máximo encontrado de $4.675 \mathrm{~m}^{3} / \mathrm{ha}$. Encontramos cifras similares en las entidades de regantes mixtas de la zona del Palancia. Estas cifras se repiten en otras zonas de la Comunidad Valenciana, en algunos sectores Canal Júcar Turia se pasa de $4.500 \mathrm{~m}^{3} / \mathrm{ha}$ a $3,000 \mathrm{~m}^{3} /$ ha para el riego de frutales, lo que les ha permitido disminuir significativamente el uso de aguas subterráneas en años normales.

Aunque mayoritariamente se producen ahorros significativos, en algunos casos se pone de manifiesto la resistencia de los agricultores a disminuir las aportaciones después del cambio de técnica de riego. En las comunidades de regantes del Vinalopó Medio (Alicante), los agricultores están empleando en torno a $3.600 \mathrm{~m}^{3} /$ ha en años húmedos y alrededor de $4.200 \mathrm{~m}^{3} / \mathrm{ha}$ en años secos para regar uva de mesa, tanto antes como después de la modernización. Las razones que parecen motivar este escaso impacto del cambio tecnológico en términos de ahorro del recurso podrían ser tres. En primer lugar, existe una cierta inercia en los agricultores a mantener una dotación hídrica similar a la que aplicaban en sus parcelas antes de la transformación, que nos ha sido expresada por los gestores de ésta y otras zonas regables ${ }^{2}$.

En segundo lugar, el incremento de la capacidad de regulación, necesario para permitir la mejora en la distribución del recurso y la recepción y mezclado de los caudales procedentes de las estaciones depuradoras de aguas residuales, está comportando un largo periodo de residencia del agua en los embalses, generando unas notables pérdidas por evaporación. Así, estas pérdidas compensan los ahorros obtenidos en las conducciones a presión que han sustituido a las antiguas canalizaciones a cielo abierto. De hecho, las diferencias entre el recurso que adquieren estas comunidades y el volumen que finalmente sirve a los usuarios se estiman todavía en volúmenes cercanos al 20\%, como demuestran los datos obtenidos en Biar o en Monforte del Cid (García-Mollá et al., 2013). Otro hecho a tener en cuenta es el de la gran cantidad de agricultores a tiempo parcial que tienen pequeñas parcelas con cultivos y chalets que concentran sus riegos en el fin de semana, sin aprovechar las ventajas que ofrecen los sistemas de goteo de alta frecuencia.

Como hemos mencionado, para algunos autores la instalación de técnicas ahorradoras puede conllevar a un aumento de la demanda de aguas de riego en la cuenca. Las características actuales de la agricultura mediterránea valenciana hacen que no sea previsible un aumento de la demanda tras la instalación del riego por goteo por varios motivos, entre el que cabe destacar los efectos predecibles del cambio climático en las regiones mediterráneas. Además, los cultivos son en su mayoría leñosos, lo que no facilita el cambio a otros cultivos más productivos a corto plazo aunque si a medio y largo plazo (es posible importantes grandes incrementos de superficie de caqui, kiwi, aguacates y otros, sustituyendo sobre todo a cítricos, melocotoneros, albaricoques). Tampoco es previsible un aumento de la superficie regada si continúa la tendencia observada en los últimos años, ya sea por el cambio de uso a urbano la construcción de nuevas infraestructuras o por las bajas rentabilidades de los cultivos en una agricultura minifundista y en un contexto de bajada de precios de los productos agrarios.

2 En el riego por gravedad el número de riegos era de 2 o 3 al año, utilizando grandes caudales en cada riego, lo que pudo crear una sensación psicológica de «inundación» que no se produce con el riego por goteo. 
No obstante, sí que se han dado casos en los que la instalación del riego por goteo ha sido asociada a una ampliación de la superficie regada. En este sentido, Sese (2012) ha analizado el caso de Montesa (Valencia), donde la transformación a riego por goteo fue impuesta como una condición por la Confederación Hidrográfica del Júcar (en adelante, CHJ) para poder ampliar las concesiones de aguas subterráneas, dando paso a una importante expansión de la superficie regada de cítricos durante la última década, cercana a las 1.000 ha. En otros casos, sin embargo, las ampliaciones no han alterado sustancialmente los aportes ni los derechos de los usuarios. Este es el caso de la Vall de Beneixama, donde la superficie regable se ha triplicado en la pasada década. En las dos entidades de riego de esta subcomarca se ha producido un abandono de los cultivos de frutales en explotaciones históricas microparceladas, situadas en el fondo del valle, en paralelo a la puesta en riego de los piedemontes ocupados por olivares, con una baja exigencia hídrica (entre $600 \mathrm{~m}^{3} /$ ha y $1.200 \mathrm{~m}^{3} /$ ha según el año). El paso a producciones menos exigentes hídricamente ha permitido que, en este caso, la ampliación del regadío y la introducción del riego presurizado se hayan ejecutado sin alterar las concesiones de aguas subterráneas previas y sin un cambio significativo en las extracciones, pero con resultados muy satisfactorios para los usuarios.

\section{IV.2. Cambios en el origen del recurso}

En las zonas donde se utilizan simultáneamente aguas superficiales y subterráneas la disminución de los aportes, debida a la utilización de técnicas ahorradoras -y en parte también a la disminución de la superficie regable-, ha permitido que se reduzca el porcentaje de agua subterránea utilizado para el riego y se aumente el uso de aguas superficiales más baratas. Así por ejemplo, durante los años finales de la década de 1990, el Sindicato de Riegos de Sagunto, que abastece varias poblaciones del Bajo Palancia, contaba con aguas de procedencia subterránea, superficial y de la depuradora municipal. Las proporciones de cada tipo de recurso variaban según años. Para el año 1995, debido a la sequía, los porcentajes fueron un 5-10\% superficial, 10-15\% depurada y el resto subterráneas (García Mollá, 2000). En la actualidad, tras el paso a riego localizado, sólo están utilizando aguas subterráneas dos municipios (Sagunto y Algimia de Alfara) y el resto de entidades de la comarca tiene suficiente con el agua superficial suministrada.

Un caso similar es la Comunidad de Regantes de Bétera, constituida en 1978 para el aprovechamiento de las aguas superficiales del Canal Principal del Campo del Turia. El Canal fue construido por el Estado para suplementar a las 34 sociedades de pozos que, hasta entonces, regaban con aguas subterráneas. Antes del proceso de modernización la mayor parte del agua utilizada era de origen subterráneo, en 1996 de los ocho riegos que se aportaban para el cultivo de cítricos, aproximadamente 5,5 eran de agua de los pozos y 2,5 de agua del canal y se suministraba más de $7.000 \mathrm{~m}^{3} / \mathrm{ha}$ y año. Actualmente, tras el proceso de modernización los aportes se han reducido a $3.600 \mathrm{~m}^{3} /$ ha y año y los pozos se utilizan únicamente en periodos de sequía.

Lo mismo ocurre en los sectores de Canal Júcar-Turia, que tras la modernización pasaron de utilizar un 40-70\% de aguas subterráneas a un 80-100\% de agua superficial. La disminución de la proporción de agua subterránea utilizada es debida por un lado al ahorro generado por el riego localizado, pero por otra parte también, a la disminución de la superficie regada. 


\section{IV.3. Cambios institucionales}

Los procesos de cambio tecnológico en los regadíos han conllevado importantes modificaciones en las prácticas de riego y en la gestión, que se han traducido en cambios institucionales a escala interna y externa en las comunidades de regantes. Por un lado, en la Comunidad Valenciana se han observado procesos recientes de fusión de entidades que unas veces han sido acelerados por los procesos de modernización y en otros casos se han visto dificultados de alguna forma e incluso paralizados. Por otra parte, a nivel interno, los cambios en los procedimientos operativos de riego y el diseño de nuevas redes de distribución han alterado las pautas de gestión tradicionales, obligando en muchos casos a redefinir las unidades hidráulicas locales y a readaptar los recursos humanos de las entidades a las nuevas necesidades.

\section{IV.3.1. Procesos de integración de entidades}

El regadío valenciano presenta una importante atomización institucional. En los sistemas de regadío histórico, abastecidos por aguas caballeras, la tradicional adscripción municipal de las instituciones de riego evitó inicialmente la configuración de un número excesivo de pequeñas entidades de riego, y si exceptuamos el caso de la Vega Baja del Segura, las grandes acequias mantuvieron órganos de gestión supramunicipales ajustados a las dimensiones de la unidad hidráulica. Sin embargo, durante el siglo XX, la intensa movilización de las aguas subterráneas por particulares o sociedades privadas, por iniciativa propia o impulsada por la administración, dio lugar a una multiplicación de las entidades de riego. En algunas localidades, la creación de estas sociedades generó además una importante intercalación parcelaria debido a la dispersión de la propiedad y provocó la configuración de redes de distribución solapadas o entrecruzadas.

El diseño y construcción de redes presurizadas podría haberse aprovechado para lograr una mayor integración de estas entidades, reduciendo los costes de construcción, mantenimiento y gestión de las infraestructuras, así como probablemente también mejorando la eficiencia de distribución. Sin embargo, las administraciones públicas han evitado intervenir en esta materia. Por lo general, su participación se ha limitado a subvencionar las transformaciones planteadas por las propias entidades de riego, sin diseñar acciones a escala comarcal o de subcuenca. Ni siquiera cuando se han desarrollado planes a mayor escala, como las infraestructuras del postrasvase Júcar-Vinalopó, se ha tratado de incentivar estos cambios institucionales, que podrían haber redundado en una mejora de la gestión local del riego y en una reducción de sus costes.

No obstante, ha habido algunos casos en los que el desarrollo de los proyectos de modernización ha estimulado el desarrollo de procesos de integración de entidades, pero este ha sido el resultado de la iniciativa de agricultores y líderes locales, a veces alentados por la CHJ. Uno de los ejemplos más significativos es el de La Vall d’Uixó (Castellón). Este municipio constituye un claro exponente de lo antes expuesto respecto a la multiplicación de pequeñas entidades de aguas subterráneas, con numerosas parcelas de diferentes entidades intercaladas y una maraña de redes de distribución. En el año 2000, tras declarar la CHJ la sobreexplotación del acuífero, la Comunidad General de Usuarios de la Vall d’Uixó impulsó 
un proceso de transformación a riego por goteo de las infraestructuras de las 18 comunidades de regantes del municipio que permitió diseñar las redes de riego, provocando diversos procesos de fusión entre entidades. De este modo se redujo a 12 el número de sociedades agrícolas de transformación (SAT) y comunidades de regantes del municipio. Además, la Comunidad General ha ido en paralelo asumiendo algunas funciones de gestión que en origen eran responsabilidad de las entidades locales, simplificando y reduciendo las cargas administrativas.

En el municipio de Villena (Alicante) ha tenido lugar un proceso exitoso de integración de entidades de riego de aguas subterráneas, auspiciado localmente. A finales de la década de 1990, diversas entidades iniciaron procesos de fusión o de absorción de entidades vecinas que desembocaron en la creación en 2001, de la Comunidad de Regantes de Villena (Figura 5). A ésta se incorporaron después otras tres SAT. La transformación a riego por goteo fue inicialmente uno de los principales factores que estimuló el proceso de fusión, pero posteriormente se convirtió en un requisito para los que querían incorporarse a la entidad. Esta condición se impuso para evitar que los costes de la modernización de las entidades que pretendían incorporarse a la nueva comunidad de regantes tuvieran que distribuirse también entre los que ya habían instalado sistemas de riego a presión. Otras entidades del municipio esperan poder incorporarse a esta entidad una vez se complete su proceso de modernización.

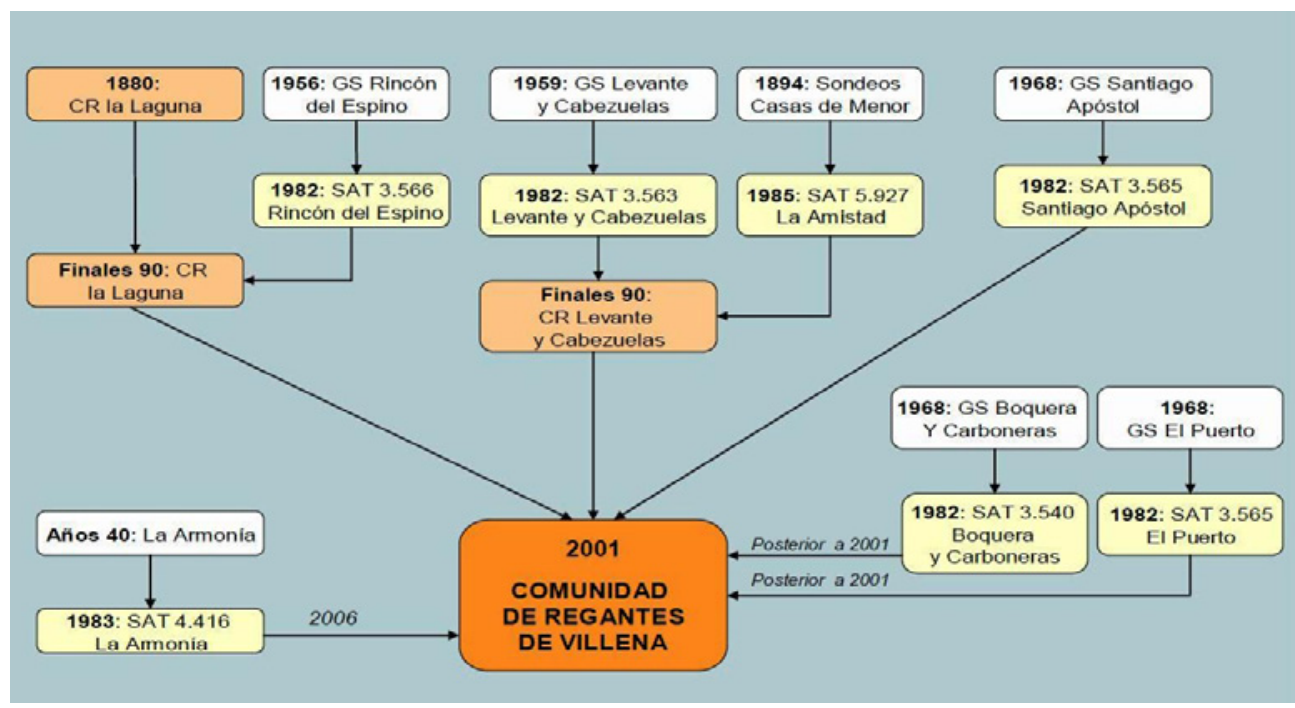

Otro ejemplo de cómo la presurización de la red ha condicionado estos procesos de fusión de entidades de riego se observa en el vecino municipio de Sax. Allí dos entidades de 
riego, la Comunidad de Regantes del Sindicato de la Villa de Sax y la SAT n 3.562 de Sax abastecen cada una, aproximadamente, a la mitad de las tierras regadas del término municipal. Comparten sede social y parte del personal, pero constituyen distintas entidades. Hubo, no obstante, un fallido intento de fusión a finales de la década de 1990. Entre los motivos que dieron al traste con este proceso, se señalan dos factores: por un lado las diferencias entre los derechos de aguas de ambas entidades, pero por otro, el diferente nivel de desarrollo que en su día llevaban los proyectos de transformación a riego por goteo de ambas entidades. De hecho, algunas de las personas consultadas manifestaban su esperanza en que, toda vez que los trabajos de modernización ya habían concluido en las dos entidades, podía resultar posible relanzar de nuevo el proceso de fusión.

En los casos de las entidades de riego que aprovechan los sobrantes de otras comunidades la integración o absorción acaba siendo irremediable, por cuanto la introducción del riego presurizado hace desaparecer las escorrentías que los alimentan. Así sucede en el Sindicato de las Partidas Arroceras de Albalat de la Ribera (Valencia), que se abastece de aguas de manantiales, pero se beneficia regularmente de los retornos de riego de la Acequia Real del Júcar. La transformación a riego por goteo de la Acequia Real va hacer desaparecer estos sobrantes. Por ello, en los próximos años, las tierras de huerta de la comunidad de Albalat de la Ribera se integrarán en la Acequia Real del Júcar como miembros de pleno derecho, mientras que las zonas de arrozal, situadas a cotas más bajas y menos dependientes de los sobrantes, mantendrán la independencia institucional.

\section{IV.3.2. Cambios en la organización del riego}

La transformación a riego por goteo ha supuesto importantes modificaciones en la organización de los sistemas de reparto de agua en las entidades que se han modernizado. Por lo general, el uso de sistemas de presurización permite el paso de sistemas de reparto mediante turnos o tandas, al riego a la demanda. Este hecho mejora notablemente el confort de los regantes, permitiendo la supresión del riego nocturno -o su automatización- y de una mejor compatibilización de las tareas agrícolas con otras actividades profesionales. No obstante, algunos de estos cambios también han sido introducidos por entidades de riego que, sin haber procedido a la presurización de la red, han construido balsas de regulación que les otorgan mayor margen de maniobra en la distribución del recurso, como ha sucedido en la Acequia de Moncada.

En unos y otros casos, la generalización de los procedimientos de distribución a la demanda han causado importantes modificaciones en las necesidades de mano de obra, al no ser necesario el regador que en algunos casos se encargaba del reparto y control de los riegos, y en otros incluso aplicaba el riego en la parcela. Estos regadores estaban incluidos a veces en la plantilla de las entidades de riego y en otras trabajaban como profesionales autónomos, al servicio de los agricultores de cada área regable. En zonas donde se ha producido una transformación generalizada al riego por goteo, como en las entidades de riego pertenecientes al Sindicato Central de Aguas del Río Mijares, esta figura prácticamente ha desaparecido.

En algunas entidades se han mantenido los regadores por las reticencias existentes a despedir a trabajadores, generalmente de avanzada edad y muchos años dedicados a la 
entidad, por lo que se ha preferido esperar a la jubilación. Esta política se ha aplicado por ejemplo en la Comunidad de Regantes de Monforte del Cid, que pese a haber completado la presurización de la red, ha optado por suprimir sólo los puestos de trabajo de aquellos empleados que alcanzan la edad de jubilación. De este modo se reduce el impacto social del ajuste tecnológico y se retrasa en el tiempo el descenso de los costes laborales de la entidad.

\section{IV.4. Efectos sobre la situación financiera de las entidades de riego}

La gran mayoría de las entidades de riego valencianas, y todas las aquí citadas, han recurrido a subvenciones públicas para realizar la inversión necesaria para el cambio de técnica de riego. Según datos aportados por la Generalitat y SEIASA Meseta Sur, durante los años 1997 a 2009 se realizaron inversiones en la trasformación tecnológica por un valor de algo más de 1.000 millones de euros, de los que cerca del $70 \%$ fueron subvencionados con fondos públicos. Las subvenciones fueron otorgadas para la trasformación de alrededor de 170.000 ha. Estas cifras parecen sobredimensionadas, al menos si las comparamos con la superficie en riego localizado en los censos agrarios de 1999, cuando ya había 101.157 ha a goteo, y las de 2009, donde no se registran más de 181.289 ha.

Si bien puede que haya razones de cálculo o calidad estadística que justifiquen esta aparente incongruencia de los datos, conocemos algunos casos en los que el motivo parece residir en una incorrecta estimación inicial de la superficie sobre la que se proyectaron las actuaciones, a veces notablemente superior al espacio sobre el cual posteriormente se ejecutaban las obras. Esto puede suceder en algunas comarcas en las que por motivos urbanísticos o por los recientes procesos de abandono de la actividad agraria la superficie en riego está disminuyendo. En estos casos el espacio a transformar se reduce antes de la materialización del proyecto. Otro motivo es que, en algunas entidades, con posterioridad a la implantación del riego por goteo hay propietarios que se resisten a introducir las nuevas tecnologías y optan por mantener el antiguo sistema de riego. Por último se han observado casos en los que se ha sobredimensionado la superficie regable para conseguir más subvenciones y/o disminuir menos la concesión, sobre todo para paliar las reducciones en épocas de sequía o prevenir los efectos del cambio climático.

Un caso especialmente llamativo es el de la Comunidad de Regantes Ríos Alcoy y Vernisa. Esta entidad tiene una superficie regable de algo más de 1900 ha -aunque actualmente sólo riegan unas 1.500- en 15 municipios de la comarca de La Safor, en Valencia. La disminución de la superficie regada ha sido debida a varios motivos, entre los que se encuentran el aumento de superficie urbana y la realización de obras públicas que han ido mermando el suelo destinado a la agricultura, en una zona costera en la que el sector turístico es muy importante. El abandono de la actividad, de una población agraria envejecida ha sido otro factor que ha podido tener influencia en este descenso.

Ahora bien, por motivos que desconocemos el proyecto se realizó para una superficie de 2.500 ha, superior incluso a la superficie regable. Las obras necesarias para la instalación de riego localizado han sido financiadas por dos entidades. Por un lado la Conselleria de Agricultura ha promovido las obras en dos sectores, financiando al 100\% la instalación de la red primaria y la inversión realizada secundaria al 40\%. Por otro lado, SEIASA ha finan- 
ciado otros dos sectores de los que han recibido una subvención del $24 \%$ y la Comunidad de Regantes pagó el 32\% de la inversión y financió el 44\% restante en 50 años con una carencia de 25 años y sin intereses.

El presupuesto total de las obras fue de 28,5 millones de euros. Esto supone una inversión total por hectárea proyectada de 11.200 euros, pero si dividimos por las hectáreas que finalmente se unieron al proyecto la cifra se eleva a más de 19.000 euros por hectárea. La entidad disponía de un préstamo para el pago de la obra y cobraba a los socios únicamente por el coste de instalar el goteo suponiendo que se modernizaba toda la superficie para la que se hizo el proyecto. Esto puede provocar que la entidad tenga serios problemas para financiar la parte de la inversión que no ha sido subvencionada, sobre todo porque se observa un acelerado abandono de las explotaciones agrarias en los municipios afectados, que además de a razones de mercado o edad de los activos, puede obedecer a los importantes gastos de gestión de la comunidad.

Otro ejemplo que ilustra las posibles dificultades futuras derivadas del proceso de modernización se produce en el sector XI del Canal Júcar Turia. En esta comunidad de regantes las obras para instalar el riego por goteo fueron realizadas y financiadas por SEIASA de la Meseta Sur. El presupuesto total de la inversión fue de 3,9 millones de $€$ de los que la comunidad de regantes financió mediante un préstamo el 32\%, SEIASA con fondos del FEOGA un $24 \%$ y el restante $44 \%$ la comunidad de regantes en 50 años con una carencia de 25 años y $\sin$ intereses.

Según los datos aportados por SEIASA el coste por hectárea modernizada ha sido, de $6.965 €$. Para pagar la parte de la inversión correspondiente a los regantes, la comunidad obtuvo un crédito de una entidad financiera, de forma que las derramas extraordinarias que aportan los regantes son empleadas en la amortización del crédito solicitado. No obstante, además del crédito comentado para hacer frente a las obligaciones actuales, que están haciéndose efectivas con la derrama superficial indicada antes, el 44\% de la inversión se deberá pagar en un plazo de 25 años, a partir del 2032, lo que supone una deuda aplazada de 69.016 $€ /$ año durante veinticinco años (122 €/ha y año). En consecuencia el endeudamiento de la entidad ha crecido notablemente, hecho que lastrará la futura viabilidad de las explotaciones, en un contexto de mercado poco favorable. El abandono de las explotaciones por pérdida de rentabilidad puede tener además un efecto de retroalimentación sobre quienes mantienen la actividad, al ser cada vez menos los socios de la entidad que deben asumir la carga del endeudamiento.

\section{IV.5. Cambios en las tarifas y costes del recurso}

La modernización de regadíos ha tenido influencia sobre los costes pagados por los agricultores por el agua de riego. Generalmente el proceso de implantación del riego localizado ha supuesto un incremento de los costes volumétricos derivados del aumento de los costes energéticos, debido a las necesidades de introducir sistemas de bombeo para conseguir la presurización de la red hidráulica. Además, los agricultores han tenido que asumir una parte variable del coste de la inversión, que conlleva también un aumento de los costes.

En algunos casos, singularmente en zonas abastecidas con aguas subterráneas, el descenso del aporte de agua en la parcela y de las pérdidas en la red ha permitido compensar el 
incremento del coste volumétrico, al reducirse significativamente las horas de bombeo en los pozos de riego. De este modo resulta posible que, en determinados ámbitos, el coste por unidad de superficie regada sea menor que antes del cambio de técnica de riego. Sin embargo, por lo general, en espacios regados con aguas superficiales, la disminución de los aportes no compensa el incremento del coste del agua por metro cúbico y el coste anual del riego por unidad de superficie aumenta.

El ejemplo de la Plana de Castelló permite comparar las tarifas pagados por el agua de riego en entidades situadas en zonas colindantes, con cultivos y condiciones edafoclimáticas similares pero con orígenes del agua diferentes (García Mollá et al, 2014). En esta comarca se han analizado los costes del agua de las entidades pertenecientes a la Comunidad General de Regantes de Vall d'Uixó (CGRVU), todas ellas utilizan aguas subterráneas y las entidades pertenecientes al Sindicato Central de Regantes del Rio Mijares (SCARM), en el que coexisten entidades tradicionales de regantes que únicamente utilizan aguas del río Mijares con otras más modernas que utilizan aguas subterráneas complementadas con aguas superficiales aportadas a través de canales realizados por el Estado. En las tablas 2 y 3 se muestran las tarifas medios del riego que pagan los socios a las entidades de riego por superficie y por volumen, antes y después de la modernización. Los costes del riego por inundación de 1997 han sido actualizados a euros de 2010, para ello se ha empleado el IPC. También se muestran los costes operativos del riego por goteo, que no incluyen la amortización de la inversión, los precios las tarifas que incluyen la amortización de la inversión pagada por los regantes y el coste total que incluye la amortización de la inversión total, es decir, la tarifa que deberían pagar los regantes si no hubiera subvenciones.

En SCARM, los costes son más bajos debido a la utilización de agua superficial del río Mijares. Los costes operativos son en estas entidades en torno al $60 \%$ de los costes totales. Este porcentaje es menor que en CGRVU debido al menor coste energético en un área provista casi exclusivamente con aguas superficiales. Antes de la modernización, los costes y los precios dependían básicamente de la procedencia de los recursos hídricos. Los costes eran más bajos en las asociaciones de usuarios provistos de agua del rio Mijares. Actualmente, este efecto ha disminuido, y los costes y las tarifas son muy similares en las entidades que riegan con aguas superficiales y mixtas, tanto por hectárea como por volumen, esto puede deberse a que, como se ha mostrado, los porcentajes de aguas subterráneas utilizadas en las entidades mixtas han disminuido notablemente.

Tabla 2

TARIFAS DE RIEGO POR GOTEO EN LA PLANA DE CASTELLÓN

\begin{tabular}{cccccccc}
\hline & \multicolumn{2}{c}{$\begin{array}{c}\text { Costes de operación y } \\
\text { mantenimiento }\end{array}$} & \multicolumn{2}{c}{ Precios del riego } & \multicolumn{2}{c}{ Coste total } & \% \\
& $€ /$ ha & $€ / \mathrm{m} 3$ & $€ /$ ha & $€ / \mathrm{m} 3$ & $€ /$ ha & $€ / \mathrm{m} 3$ & $\begin{array}{c}\text { recuperación } \\
\text { de costes }\end{array}$ \\
\hline CGRVU & 1.135 & 0,28 & 1.280 & 0,32 & 1.563 & 0,39 & 81,9 \\
\hline Mixtas & 617 & 0,17 & 869 & 0,24 & 1.138 & 0,32 & 76,3 \\
Superficiales & 768 & 0,22 & 938 & 0,26 & 1.117 & 0,31 & 84,0 \\
SCARM & 690 & 0,19 & 902 & 0,25 & 1.128 & 0,31 & 80,0 \\
\hline
\end{tabular}


Tabla 3

COSTES DEL RIEGO POR INUNDACIÓN EN LA PLANA DE CASTELLÓN

\begin{tabular}{ccccc}
\hline & \multicolumn{2}{c}{ Coste 1997 } & \multicolumn{2}{c}{ Coste 2010 } \\
& $€ /$ ha & $€ / \mathrm{m}^{3}$ & $€ /$ ha & $€ / \mathrm{m}^{3}$ \\
\hline$C G R V U$ & 1.772 & 0,2 & - & - \\
\hline Mixtas & 1.249 & 0,17 & 840 & 0,08 \\
Superficiales & 501 & 0,07 & 293 & 0,04 \\
SCARM & 839 & 0,12 & 343 & 0,04 \\
\hline
\end{tabular}

Los costes volumétricos $\left(€ / \mathrm{m}^{3}\right)$ han aumentado considerablemente en todas las asociaciones de regantes, incluso si sólo tenemos en cuenta los costes operativos. Las asociaciones que utilizan aguas superficiales son las que han tenido un mayor incremento de las tarifas volumétricos. La disminución de los consumos unitarios ha compensado en parte este incremento, así, tanto en las entidades que riegan con aguas subterráneas como en las que riegan con aguas mixtas los agricultores han visto una rebaja en la tarifa del riego por unidad de superficie. Son las comunidades de regantes con aguas superficiales en las que se produce un aumento de las tarifas del riego por unidad de superficie, esto es debido a que antes de la modernización los precios del riego eran más bajos, al no tener costes energéticos significativos para la obtención del recurso. Se observa por tanto, un impacto diferente entre aguas superficiales y subterráneas, como ha detectado Jackson (2010).

El porcentaje de recuperación de costes que se muestra en la tabla 2 es el porcentaje del precio que pagan los regantes sobre la tarifa total de llevar el agua a la parcela. La utilización de subvenciones para incentivar el uso de técnicas que mejoren la eficiencia en el uso del agua de riego lleva a disminuir el porcentaje de recuperación de costes. Como muestran Dono et al (2012), en algunas ocasiones, la búsqueda de altos porcentajes de recuperación de costes puede estar en conflicto con las mejoras de la eficiencia, dos objetivos que deben alcanzarse según la DMA. Esto es especialmente importante en las comunidades de regantes tradicionales que riegan con aguas superficiales suficientes en años normales, en las que las tarifas del riego han aumentado considerablemente con la modernización y no tendrían alicientes para realizar la transformación si no existieran ayudas públicas (García Mollá et al, 2014).

Otro caso interesante es el del Canal Júcar-Turia, abastecido por aguas mixtas, donde coexisten zonas regadas por gravedad y por goteo. En las explotaciones regadas por gravedad, los costes del riego soportados por los agricultores por unidad de superficie han aumentado considerablemente desde 1998 , y ha pasado en términos reales de $325 € /$ ha a $746 € /$ ha (equivalentes a $0,075 € / \mathrm{m}^{3}$ y $0,166 € / \mathrm{m}^{3}$ ). Este incremento refleja el alza de los costes de mano de obra, de la energía para la extracción de agua de los pozos, pero también los derivados de una pérdida de eficiencia en la distribución, al quedar pocas parcelas y muy dispersas con esta práctica de riego. Sin embargo, las explotaciones que ya emplean el riego localizado, tienen un coste de $210 € /$ ha, que se incrementan a $570 € / \mathrm{ha}\left(0,19 € / \mathrm{m}^{3}\right)$ al incluir los costes de amortización de las obras de transformación. 
Esta disparidad en una misma entidad de riegos es relativamente frecuente, debido a que las operaciones de transformación pueden prolongarse durante varios años según las condiciones de financiación, ritmo de ejecución de los proyectos y grado de implicación de los usuarios. Existe una casuística muy variada de respuestas de las entidades de riego ante estas situaciones, desde las que prohíben en sus ordenanzas mantener el riego a manta, como en el caso de Pinar Alto (Villena), hasta las que dejan cierta libertad a los usuarios para continuar con las prácticas de inundación, como en Senyera o Sax. En algún caso, las entidades de riego giran una factura con una leve penalización a los que efectúan el riego a manta, para tratar de estimular la adopción del riego localizado y poder simplificar la gestión de la comunidad de regantes, como en Vila-real. En otros lugares, como en Novelda, los regantes que desean seguir practicando el riego a manta están obligados a mantener por si mismos las acequias y deben efectuar los pagos 20 días antes de regar. Se trata de procedimientos a través de los cuales la entidad busca estimular la incorporación de estos regantes al sistema de riego presurizado.

\section{CONCLUSIONES}

Los regadíos valencianos han afrontado en las tres últimas décadas un cambio tecnológico sin precedentes. Probablemente desde la época islámica no hemos asistido a ningún proceso de innovación tan significativo por sus implicaciones en las prácticas de riego. En cuanto a su impacto territorial, la difusión de las tecnologías de riego localizado es sólo comparable al que tuvieron, a lo largo del siglo XX, la generalización de las bombas a motor. En este proceso de cambio tecnológico se distinguen dos etapas. Una primera, anterior a 1994, que responde al interés y empuje de la iniciativa privada (Ramón Morte, 1994, 1995), y un proceso posterior, responsable de la transformación de más de 130.000 ha, con un destacado apoyo público.

En esta segunda etapa, la confluencia de unas incuestionables necesidades hídricas con determinados compromisos y estrategias políticas precipitó el desarrollo de una activa promoción pública del cambio tecnológico. Este compromiso público no ha contado con un análisis previo que permitiera a las administraciones -y también a los usuarios- ser más selectivos en sus inversiones y controlar la eficiencia del esfuerzo financiero en términos de cumplimiento de objetivos. Buena parte del apoyo financiero se prestó sin la existencia de suficientes estudios previos o auditorías que valoraran, para cada caso, los ahorros estimados en consumo de agua y energía, por lo que junto a experiencias muy exitosas podemos encontrar otros casos donde la rentabilidad de la inversión es cuanto menos dudosa. Hoy día no conocemos si existieron criterios técnicos que priorizaron las subvenciones para las inversiones más necesarias y, en cualquier caso, si los hubo, deberían haberse hecho públicos. Este hecho es particularmente relevante cuando, como hemos visto, han existido importantes diferencias en las subvenciones otorgadas a diferentes entidades de riego, que deberían haber estado ligadas a criterios objetivos de beneficio o ahorro esperado. También hay que lamentar que la administración no fuera más allá de una política clientelar de concesión de ayudas públicas y no tratara de fomentar los procesos de fusión de entidades y racionalización de las redes de riego, que hubiera redundado en mayores niveles de ahorro y en una considerable reducción de los costes de gestión. 
Por lo que respecta al ahorro de recursos hídricos, y a escala de comunidades de regantes, existe una cierta unanimidad en los casos de estudio que hemos considerado, y en muchos casos se han alcanzado ahorros importantes, como los registrados en la citricultura de la Plana de Castelló. La orientación productiva de los regadíos valencianos facilita que la implantación del riego localizado no genere los incrementos en el consumo observados en otros ámbitos por un posterior cambio de cultivo. Otra cosa es el destino que con posterioridad tengan los recursos ahorrados y que finalmente se generen ahorros a escala de cuenca. Por el momento, la única mejora observada es la reducción de las extracciones de aguas subterráneas, que en algunos casos, como en la Vall d'Uixó, ha redundado en una recuperación de los acuíferos.

El ahorro energético es por el contrario, muy limitado, cuando no se ha generado un incremento de los costes del riego. Por lo general se observa un aumento de los costes energéticos que sólo en algunas entidades abastecidas por aguas subterráneas ha podido ser compensado por las reducciones de las extracciones de agua. Sin embargo, en zonas de aguas superficiales los resultados suelen ser bastante negativos, por lo que parece desaconsejable mantener estas políticas de promoción sobre los regadíos tradicionales, salvo en casos excepcionales en los que, como sucede en la Acequia Real del Júcar, la presurización se consigue por gravedad.

Son precisamente los regadíos tradicionales de aguas superficiales donde hoy día se conserva la mayor proporción de tierras con riego por gravedad. Se trata de comunidades en las que muy recientemente se viene observando un proceso de abandono de explotaciones y una falta de relevo generacional, que puede lastrar la amortización de las inversiones. Por ello, en el futuro, más que una política indiscriminada de promoción del cambio tecnológico, se hace necesaria la aplicación de medidas previas de evaluación y análisis de los sistemas de riego, destinadas tanto a determinar las capacidades de ahorro del recurso, como las afecciones sobre el consumo energético y la viabilidad económica de las inversiones.

\section{BIBLIOGRAFÍA}

ALARCÓN, J. (2011): «Evaluación de la eficiencia de un proyecto típico de modernización de regadíos», Revista Española de Estudios Agrosociales y Pesqueros, 230, 119-145.

ALCÓN, F.; ARCAS, N.; DE MIGUEL, M.D. y FERNÁNDEZ-ZAMUNDIO, M.A. (2009): «Adopción de tecnologías ahorradoras de agua en agricultura», en Gómez Limón, J.A. et al. La economía de agua de riego en España. Una perspectiva regional, Almería, Fundación Cajamar.

ALLAN, T. (1999): «Productive efficiency and allocative efficiency: why better water management may not solve the problem», Agricultural Water Management, 40 (1), 71-75.

BROOKS, D.B. (1997): «Water demand management: conceptual framework and policy implementation», Brooks, D.B., Rached, E.: Saade, M. (eds.), Managemnet of water demand in Africa and Middle East: current practices and future needs, Ottawa, Canada, International Development Research Centre.

CARLES J. (1997): «La Administración Pública del Agua», en López-Gálvez J. y Naredo J. M. (Ed). La gestión del agua de riego. Fundación Argentaria. Visor (Dis. S.A). 
CARLES, J. y GARCÍA-MOLLÁ, M. (2003): «La coherencia de las instituciones y los modelos de uso del agua», en Albiac, J. (Ed), Los instrumentos económicos en la gestión del agua en la agricultura, Madrid, Mundiprensa, pp. 115-127.

CARRILLO-COBO M.T., RODRÍGUEZ-DÍAZ J.A. y CAMACHO E., (2010): «The role of energy audits in irrigated areas. The case of 'Fuente Palmera' irrigation district (Spain)», Spanish Journal of Agricultural Research, 8 (2), 152-161.

COROMINAS, J. (2008): «¿Modernización o reconversión de regadíos? Dimensiones socioeconómicas, ambientales y territoriales», VI Congreso Ibérico Sobre Planificación y Gestión del Agua, Vitoria, Fundación Nueva Cultura del Agua.

COROMINAS, J. (2009): «Agua y energía en el riego en la época de la sostenibilidad», Jornadas de Ingeniería del Agua, Madrid, Fundación para el Fomento de la Ingeniería del Agua.

COROMINAS, J. (2011): «Análisis de las modernizaciones de regadíos en Andalucía», Congreso Agricultura, agua y energía, Madrid, ADECAGUA.

COTS, L. (2011): Desarrollo y calibración de un modelo de simulación de recursos hídricos aplicado a la cuenca del río Corb dentro de la zona regable de los canales de Urgell (Lleida), Tesis doctoral, Universitat de Lleida.

DEL MORAL, L. (2009): «Changing discourses in a modern society», en Garrido, A. y Llamas, M.R. (Eds.), Water policy in Spain, London, Taylor and Francis, pp. 85-93.

ESCRIBANO, M.J. (2006): Análisis de la adopción de tecnologías de riego en contextos de incertidumbre: aplicación a la horticultura del Valle de Guadalhorce, Tesis doctoral, Universidad de Córdoba.

ESTEVAN, A. (2008): Herencias y problemas de la política hidráulica española, Bilbao, Bakeaz/FNCA.

FRUTOS MEJÍAS, M.L., CASTELLÓ PUIG, A., HERNÁNDEZ NAVARRO, M.L. y RUIZ BUDRÍA, E. (2008): «La modernización de los regadíos en Aragón: acciones y perspectivas», en Gómez Espín, J.M., Martínez Medina, R. (Eds.), Los espacios rurales españoles en el nuevo siglo: actas XIV Coloquio de Geografía Rural, Universidad de Murcia, pp. 111-126.

GALLEGO BONO, J.R. (1996): «Instituciones, aprendizaje y liderazgo en la difusión de innovaciones: una interpretación de la desigualdad implantación del riego por goteo en la citricultura valenciana», Revista Española de Economía Agraria, 175, 199-228.

GARCÍA-MOLLÁ, M., SANCHIS-IBOR, C., AVELLÀ, L. y CARLES, J. (2012): «Effets de la modernisation sur les terres irrigables méditerranéennes espagnoles» en De l'eau agricole à l'eau environnementale. Résistance et adaptation aux nouveaux enjeux de partage de l'eau en Méditerranée, Quae, pp. 99-112.

GARCÍA-MOLLÁ, M., SANCHIS-IBOR, C., ORTEGA, M.V. y AVELLÀ, L. (2013): «Irrigation associations coping with drought: The case of four irrigation districts in Eastern Spain», Schwabe, K.; Albiac, J.; Connor, J.D., Hassan, R.M., Meza, L. (Eds.) Drought in Arid and Semi-Arid Regions. A multi-disciplinary and Cross-Country Perspective, New York, Springer, pp. 101-121.

GARCÍA-MOLLÁ, M., ORTEGA, M.V., SANCHIS-IBOR, C. y AVELLÀ, L. (2014): «The effects of irrigation modernization on the cost recovery of water in the Valencia Region (Spain)». Water Science \& Technology: Water Supply, 14 (3), 414-420. 
GIL MESEGUER, E. (2010): «La Región de Murcia, un laboratorio de experiencias de ahorro y eficiencia en el uso del agua: la modernización de sus regadíos, entre las políticas agraria y ambiental de la Unión Europea», Papeles de Geografía, 51-52, 131-145.

GIL OLCINA, A. y DEL AMOR GARCÍA, F.; (2004): «Modernización de regadíos y difusión del riego localizado en la Cuenca del Segura», en La cultura del agua en la Cuenca del Segura. Murcia, Fundación CajaMurcia, pp. 373-402.

GÓMEZ ESPÍN, J.M. (1997): «El regadío en el umbral del siglo XXI: planes de mejoras y modernización», Papeles de Geografía, 25, 75-102.

GÓMEZ ESPÍN, J.M; GIL MESEGUER, E. y GARCÍA MARÍN, R. (2007a): El antes y después de la modernización de regadíos. La experiencia de Mula, Murcia, Universidad de Murcia y Consejería de Agricultura y Agua de la Comunidad Autónoma de la Región de Murcia.

GÓMEZ ESPÍN, J.M; GARCÍA MARÍN, R. y GIL MESEGUER, E. (2007b): «Modernización de regadíos con aguas subterráneas en ámbitos semiáridos», $M+A$. Revista Electrónica de Medioambiente, 3, 1-22.

GÓMEZ ESPÍN, J.M. (2011): «Marco de la modernización de regadíos. Políticas de ahorro y eficiencia en el uso del agua para el riego en la Cuenca del Segura y en otras cuencas hidrográficas», en Gómez Espín, J.M., López Fernández, J.A. y Montaner Salas, M.E. (Coord.) Modernización de regadios: sostenibilidad social y económica. La singularidad del Trasvase Tajo-Segura, Universidad de Murcia, pp. 79-100.

GÓMEZ-LIMÓN, J.A. y PICAZO-TADEO, (2012): «Irrigated Agriculture in Spain: Diagnosis and Prescriptions for Improved Governance», International Journal of Water Resources Development, 28 (1), 57-72.

HARDY, L. y GARRIDO, A. (2010): «Análisis y evaluación de las relaciones entre el agua y la energía», Papeles de Agua Virtual, 6, Madrid, Fundación Botín.

JACKSON, T.M.; KHAN, S. y HAFEEZ, M. (2010): «A comparative analysis of water application and energy consumption at the irrigated field level», Agricultural Water Management, 97 (10), 1.477-1.485.

LECINA, S., ISIDORO, D., PLAYÁN, E. y ARAGÜÉS, R. (2010a): Irrigation modernization in Spain: Effects on water quantity and quality-A conceptual approach, International Journal of Water Resources Development, 26, 265-282.

LECINA, S., ISIDORO, D., PLAYÁN, E. y ARAGÜÉS, R. (2010b): «Irrigation modernization and water conservation in Spain: The case of Riegos del Alto Aragón», Agricultural Water Management, 97, 1.663-1.675.

LÓPEZ FERNÁNDEZ, J.A. y GÓMEZ ESPÍN, J.M. (2008): «Efectos de la sequía en la modernización de regadíos de Mula», en Gómez Espín, J.M. y Martínez Medina, R. (Eds.) Los espacios rurales españoles en el nuevo siglo. Actas del XIV Coloquio de Geografia Rural, Universidad de Murcia, pp. 145-160.

LÓPEZ-GUNN, E. (2009): «Agua para todos: A new regionalist hydraulic paradigm in Spain» Water Alternatives, 2 (3), 370-394.

LÓPEZ-GUNN, E.; DUMONT, A. y VILLARROYA, F. (2012a): «Tablas de Daimiel National Park and groundwater conflicts», en De Stefano, L. y Llamas, R. Water, Agriculture and the Environment in Spain: can we square the circle?, Madrid, Fundación Botín, pp. 259-218. 
LÓPEZ-GUNN, E.; ZORRILLA, P.; PRIETO, F. y LLAMAS, R. (2012b): «Lost in translation? Water efficiency in Spanish agriculture», Agricultural Water Management, 108, 83-95.

LÓPEZ-GUNN, E.; MAYOR, B. y DUMONT, A. (2012c): «Implications of the modernization of irrigation systems», en De Stefano, L. y Llamas, R. Water, Agriculture and the Environment in Spain: can we square the circle? Madrid, Fundación Botín, pp. 241-255.

LÓPEZ ONTIVEROS, A. (1997): «El regadío, salvación de la patria y fuente de felicidad según los Congresos Nacionales de Riego (1913-1936)», Demófilo, 27, $27-64$.

MAGRAMA (2002-2013): Encuesta sobre superficies y rendimientos de cultivo. ESYRCE. Resultados. Madrid, Secretaría General Técnica Subdirección General de Estadística.

MARTÍNEZ-FERNÁNDEZ, J. y ESTEVE, M.A. (Eds.) (2002): Agua, regadío y sostenibilidad en el Sudeste ibérico, Bilbao, Bakeaz.

MELGAREJO, J. (1995): «La intervención del Estado en la Cuenca del Segura 1926-1986», Alicante, Generalitat Valenciana-Institut Juan Gil-Albert.

MELGAREJO, J, (2009): «Efectos ambientales y económicos de la reutilización del agua en España», CLM Economía, 15, 245-270.

MORALES GIL, A. y HERNÁNDEZ HERNÁNDEZ, M. (2010): «Mutaciones de los usos del agua en la agricultura española durante la primera década del siglo XXI», Investigaciones Geográficas, 51, 27-51.

NARANJO, J.E. (2010): «Problemática de la modernización de regadíos», XII Congreso Nacional de Comunidades de Regantes, Tarragona, http://www.fenacore.org/congresotarragona/wp-content/uploads/2009/10/ponencia-3-J.E.Naranjo.pdf.

ORTEGA, N. (1999): «La política hidráulica española hasta 1936», en Garrabou, R. y Naredo, J.M. (Eds.), El agua en los sistemas agrarios. Una perspectiva histórica, Madrid, Fundación Argentaria, pp. 159-180.

PERRY, C. J. (1999): «The IWMI water resources paradigm - definitions and implications», Agricultural Water Management, 40, 45-50.

PERRY, C.J., STEDUTO, P., ALLEN, G.R. y BURT, C.M. (2009): «Increasing productivity in irrigated agriculture: Agronomic constraints and hydrological realities», Agricultural Water Management, 96 (11), 1.517-1.524.

PLAYÁN, E. (2002): «El potencial de la rehabilitación, modernización y conservación de sistemas de riego para un mejor uso del agua», en Seminario Internacional El agua de riego a debate, Córdoba, Fundación para el Fomento de la Ingeniería del Agua, http://hdl. handle.net/10261/8987.

PLAYAN, E. y MATEOS, L. (2006): «Modernization and optimization of irrigation systems to increase water productivity», Agricultural Water Management, 80, 100-116.

RAMÓN MORTE, A. (1994): «Aplicación de riego localizado y economía del agua en la modernización de la agricultura valenciana», Boletín de la Asociación de Geógrafos Españoles, 18, 97-110.

RAMÓN MORTE, A. (1995): Tecnificación del regadío valenciano: análisis territorial de la difusión del sistema del regadío localizado, Madrid, Ministerio de Agricultura, Pesca y Alimentación.

RICO AMORÓS, A. (2010): «Plan Hidrológico Nacional y Programa A.G.U.A.: repercusión en las regiones de Murcia y Valencia», Investigaciones Geográficas, 51, 235-267. 
RODRÍGUEZ-DÍAZ, J.A.; PÉREZ-URRESTARAZU, L.; CAMACHO-POYATO, E. y MONTESINOS, P. et al. (2011): «The paradox of irrigation scheme modernization: more efficient water use linked to higher energy demand», Spanish Journal of Agricultural Research, 9 (4), 1.000-1.008.

SALES, V. (1999): «Terra i societat en l'horta de la Reial Séquia de Montcada». Mètode. Revista de difusió de la investigació, 22, 28-29.

SANCHIS IBOR, C.; GARCÍA-MOLLÁ, M.; AVELLÀ, L. y CARLES, J. (2011): «Reaching the limits of water resources mobilisation: Irrigation development in the Segura river basin, Spain», Water Alternatives, 4 (3), 256-278.

SAURÍ, D. y DEL MORAL, L. (2001): «Recent developments in Spanish water policy. Alternatives and conflicts at the end of the hydraulic age», Geoforum, 32, 351-362.

SESE MÍNGUEZ, S. (2012): Perspectives of different stakeholders to implement drip irrigation systems and its consequences for land and water use. A case study in Cànyoles river basin, Valencia (Spain), M.Sc. Thesis, Irrigation and Water Engineering Group, Wageningen University.

SECKLER, D. (1996): The new era of the water resources management, Research Report 1, Sri Lanka, International Irrigation Management Institute.

SWYNGEDOUW, E. (1999): «Modernity and Hybridity: Nature, Regeneracionismo, and the Production of the Spanish Waterscape, 1890-1930», Annals of the Association of American Geographers, 89 (3), 443-465.

SWYNGEDOUW, E. (2013): «Into the Sea: Desalination as a Hydro-Social Fix in Spain», Annals of the Association of American Geographers, 103 (2), 261-270.

VENOT, J.P.; ZWARTEVEEN, M.; KUPER, M.; BOESVELD, H.; BOSSENBROEK, L.; VAN DER KOOIJ, S.; WANVOEKE, J.; BENOUNICHE, M.; ERRAHJ, E.; DE FRAITURE, C. y VERMA, S. (2014): «Beyond the promises of technology: a review of the discourses and actors who make drip irrigation», Irrigation and Drainage, 63, 186-194.

WARD, F. y PULIDO, M. (2008): «Water conservation in irrigation can increase water use», Proceedings of the National Academy of Sciences, 105 (47), 18.215-18.220.

WINPENNY, J.T. (1997): «Demand management for efficient and equitable use», Kay, M.; Franks, T., Smith, L. (Eds.), Water: Economics, Management and Demand, London, E \& FN Spon. 
